\title{
Humour in popularisation: Analysis of humour-related laughter in TED talks
}

\author{
Giuseppina Scotto di Carlo
}

University of Naples Federico II

"Man is the only animal that laughs and weeps;
for he is the only animal that is struck
with the difference between what things are,
and what they ought to be."
William Hazlitt (1964[1891])

\begin{abstract}
This paper investigates the role of humour in TED talks, which are popularising speeches aiming at knowledge dissemination. Through the analysis of humour used in Eugene Cordero's 2012 talk 'Improv Everywhere: A TED speaker's worst nightmare', Sebastian Wernicke's 'Lies, damned lies and statistics (about TED talks)', and Julia Sweeney's 'It's time for 'The Talk", the paper analyses TED talks as an innovative tool of popularisation, which breaches the typical triangularisation 'scientist-mediator-audience', bringing scientists directly into contact with their audiences. Using classifications of humour theories described by Raskin (1985) and Attardo (1994), the paper analyses how humour in TED talks arises from a pleasant psychological shift of incongruity, when it is the "consequence of the discrepancy between two mental representations"; from a sense of superiority, when a person laughs about his/her own misfortunes or of others; or from a release reaction, when laughter is used to release tensions deriving from taboo topics, such as sexuality, politics, and religion. The talks show how humour is an endemic feature of this genre of popularising texts. In contrast with other forms of 'canonical' popularisation, these talks are not only delivered in a simple, clear, original, and relevant way, but also in a way that is enjoyable for the audience, which actively interacts with the speaker through humour.
\end{abstract}

Key words: Ted talks; popularisation; humour; scientists-audience interactions. 


\section{Introduction and aims}

This paper investigates the role of humour in TED talks, which are popularising speeches aiming at knowledge dissemination. Popularisation "is a social process consisting of a large class of discursive-semiotic practices [...] aiming to communicate lay versions of scientific knowledge" (Calsamiglia \& van Dijk 2004: 371).

Only during the last decades, scientific communication, previously conducted through press, radio, and television, is increasingly finding new outlets online. While some sources only create an online version of materials previously published in print, others recontextualize their texts adapting them to the web. This is the case of TED talks, a non-profit organisation devoted to the dissemination of 'Ideas Worth Spreading'. 'TED began in 1984 as a conference dedicated to the dissemination of Technology, Entertainment, and Design (TED), but in 2006 it started hosting the videos of the conference talks on its website and on youtube.com, eventually becoming a new spoken web-based genre. These talks constitute an innovation within innovation, as they are a new tool of popularisation that breaches the typical 'scientistmediator-audience' triangularisation, bringing scientists directly into contact with their audiences.

An important factor of these talks is their accessibility through the internet. Before 2006, the TED talks were available only to the limited group of those who had the possibility to participate in the conferences. The internet medium has opened a new frontier: it allows these videos to reach a potentially world-wide audience, to become highly 'viral'. Their fame increases through emails, forums, blogs, social networks, as well as newspapers and television programmes.

New media require knowledge dissemination to be presented as a captivating and enjoyable show, but retaining a primary proactive purpose that goes beyond the negative connotation that genres like infotainment and edutainment are assuming today.

In the light of the above, this study will focus on the use of humour in TED talks, as it seems an endemic characteristic of these speeches, because it differentiates this form of popularising speeches from the 'first generation' canonical popularising texts.

\section{Humour}

Humour and laughter are "cultural universals [...] a condition of our humanity" (Oring 2003).

This is why the study of humour has attracted the interest of researchers for centuries, drawing insights from several fields. Originally studied within the area of rhetoric, nowadays humour is a pervasive phenomenon of the new media. Whether it is used as a form of entertainment, a marketing strategy, or a strategy to say something unpleasant without being censured, humour in the media deserves attention both as a linguistic and cultural phenomenon.

Humour actually permeates nearly every aspect of society; it has been the theme of extensive studies that have investigated the mechanisms underlying humour and its multiple functions as a communicative tool. For instance, according to Hertzler (1970: 127), humour has a very influent role in shaping a group's status system, because it can function as a social equaliser or it can serve to reinforce and maintain status differences. In particular, with regard to the levelling function, Hertzler suggests that humour used in a communicative context involving interlocutors with different statuses can open communication and push social barriers into the background, achieving a feeling of commonality. For Meyer (2000: 317), humour in communication can act as a "lubricant" when it smoothes "the way and integrate a 
speaker into a greater level of credibility within a group, but it can also ruffle feathers and cause social friction and conflict". Meyer calls this ambiguity the "double-edged sword of humour". Depending on these factors, humour can be a unifier, creating positive relations between participants (with a function of identification or clarification), or alternatively it can divide the interlocutors and create a negative environment that does not facilitate communication (differentiation or enforcement).

Humour is also used in professional contexts and a very interesting field of investigation is the use of humour in science. At first glance, the topics of science and humour could seem to be wholly unrelated. The public perception of science and its practitioners is one of inherent seriousness, as their profession requires strict protocols and scientific method. As Scott (2012: 11) reported:

\begin{abstract}
Barman (1997) notes that children, when asked to draw what scientists look like, tend to conceive of scientists as lab-coat sporting, bespectacled Caucasian males found only inside laboratories. Further observations by McAdam (1990) suggest that this is a pervasive view of scientists sometimes developing from a comedic "mad scientist" archetype during early education before settling into the more prosaic 'white coated' version. David Chambers (1983) has popularised a "Draw-a-Scientist" test that was initially trialled in Australia, Canada and the USA, in which school children are asked to draw their conception of what a scientist looks like and where they work. These impressions appear to transcend geographic, racial and socio-economic strata, at least within western nations (Finson 2003). The test has been shown to produce different results when deployed in different cultural groups, but a common thread of misconception of science still persists (Farland-Smith 2009). What is more surprising is how these views persist into later life (McAdam 1990).
\end{abstract}

However, the combination of objective scientific investigation and the pleasant emotional responses to humour can become a powerful educational tool. This is true not only in the context of the scientific community and formal education, but also, and especially, in public communication of science in the media.

Though the use of humour in the new media has been thoroughly analysed by scholars such as Chovanec \& Ermida (2012), there is little systematic research on the role of humour in popularisation (e.g. Donovan 2012); and, thus, this field still needs to be explored. This is probably due to the fact that this field is still influenced by the canonical view according to which science and popularisation should be kept separated. This may explain the negative connotation given to phenomena such as infotainment, described by Demers (2005: 143) as "information-based media content or programming that also includes entertainment content in an effort to enhance popularity with audiences and consumers". Some critics consider TED talks a form of infotainment, as they are presented in an episodic format that helps simplify otherwise complex information. Information given in this context is easier to comprehend than hard news broadcasts.

However, this seems quite a reductionist perspective. TED talks are actually more than infotainment: citizens come together to debate pressing issues and topics of global interest, but with a proactive purpose that goes beyond the concept of an entertaining show. As a matter of fact, the TED talk coach Phil Waknell, who is also the Chief Inspirer at Ideas on Stage, ${ }^{2}$ explains that this form of popularisation is based on a very thoroughly studied way of delivering speeches. Though each talk is unique, there are some characteristics that these talks all share, which can be summarised in the "S.C.O.R.E. theory": "Simple, Clear, Original, Relevant, Enjoyable'. In Waknell's words ${ }^{3}$ :

If you can take a simple, original and relevant message, and deliver it in a clear, original and enjoyable way, then you will certainly S.C.O.R.E. with your audience. 
In particular, an important feature of TED talks is their 'enjoyability', enhanced through the use of humour. This feature is explained by Waknell (2012) as the most difficult but most important element of TED talks:

People do not pay good money to go to TED to be bored. They want to be entertained, and TED audiences know that if you enjoy something, then you are more attentive; and if you are more attentive, you take more in and remember more.

Humour is related to pathos, i.e. to the ways of personally engaging the audience appealing to emotions. In fact, humour helps the audience connect with the speaker, through an emotional rather than intellectual reaction:

Smiling and laughing both release endorphins which make us happier [...], and those endorphins take a while to dissipate - therefore the listeners will still feel they are enjoying your presentation after you've moved on from the humour, and they will be more likely to continue paying attention if they are enjoying it. (Waknell 2012)

Engaging with the audience is fundamental, as it allows to be understood, respected, and remembered. This can explain why most jokes and humorous gags are placed especially at the beginning or the end of these talks, because the audience is more likely to remember it since "the mind has a tendency to retain happy memories and release boring ones" (Waknell 2012).

\section{Corpus and theoretical framework}

This paper is based on the analysis of three TED talks retrieved from a corpus elaborated for a departmental research project of the Department of Modern Philology of the Federico II University of Naples (Italy), headed by Bongo, Caliendo, and Rasulo, including the transcriptions of TED talks presented in English between 2006 and 2012, for a total of about three million words and divided into five macro-areas: Arts and Design, Business, Education and Culture, Politics and Global issues, and Science and Technology. The case studies have been chosen among a sub-corpus of the 25 most seen videos from 2006-2012 rated as 'funny' by the TED audience community through the TED rating system. In fact, users are allowed to award three points among fourteen adjectives-variables to each video-talk (jaw-dropping, persuasive, courageous, ingenious, fascinating, inspiring, beautiful, funny, informative, ok, unconvincing, confusing, longwinded, and obnoxious). This enables the website not only to give visualisation data, but also to sort its content according to any of the 14 variables.

As the study is both quantitative and qualitative, it relies on the use of AntConc software and the theoretical framework mainly provided by the classifications of humour theories described in Raskin (1985) and Attardo (1994). According to these classifications, humour can arise from a pleasant psychological shift of incongruity, that is to say that humour is the "consequence of the discrepancy between two mental representations, one of which is an expectation and the other is some other idea or a percept"; humour can also derive from a sense of superiority, when a person laughs about the misfortunes of others, because these misfortunes assert the person's superiority on the background of shortcomings of people or situations that are made fun of. A particular kind of this humour is self-deprecation, which is used to put the speaker and the audience at the same level. Finally, humour and laughter can be a release reaction, when laughter is used to release tensions or to make one feel liberated when talking about taboo topics, such as sexuality, politics, and religion. These three theories 
will be used to explain humour used in the three top-rated talks in terms of 'funniness': Eugene Cordero's 2012 talk 'Improv Everywhere: A TED speaker's worst nightmare', Sebastian Wernicke's 2010 talk 'Lies, damned lies and statistics (about TED talks)', and Julia Sweeney's 2010 talk 'It's time for 'The Talk'.

Drawing upon Gumperz's (1982) theories, the study also focuses on how humour is used to establish the speaker-audience relationship and to negotiate identities. The aim is to show how these speakers use humour to achieve their communicative goals, being ultimately influenced by the social context of TED itself, in which the speakers-scientists have to move from 'working behind the scenes' to get 'under the limelight', restructuring the form of their canonical social role to interact in the popularised science context.

\section{Findings}

As previously said, in TED talks humour is used as an appeal to pathos, ${ }^{4}$ which causes the audience to respond emotionally to an issue and to identify with the speaker's point of view, creating a connection between the two parties. For this reason, pathos is a very powerful tool, as it can be used to move the audience to decision or action, which go beyond the instance of humour.

Humour used in TED talks evokes joy, surprise, but also calmness and friendship. It can be used as a strategy to increase the audience's attention because it gives positive feelings, and, thus, it not only boosts emotions, but also the speaker's credibility. Attardo classifies "humor-related laughter" in three groups, in which laughter is generated by a cognitive, social, or psychoanalytical reason, as can be seen in Table 1 below:

Table 1. Attardo's (1994: 47) Families of Humor Theories.

\begin{tabular}{|c|c|c|}
\hline \multicolumn{3}{|c|}{ Attardo's (1994: 47) Families of Humor Theories } \\
\hline Cognitive & Social & Psychoanalytical \\
\hline Incongruity & Hostility & Release \\
\hline Contrast & Aggression & Sublimation \\
\hline & Superiority & Liberation \\
\hline & Triumph & Economy \\
\hline & Derision & \\
\hline & Disparagement & \\
\hline
\end{tabular}

The following paragraphs will focus on three case studies as examples of how TED speakers use humour to boost their presentations, appealing to humour deriving from incongruity, derision, or release.

\subsection{Humour from incongruity: 'Improv Everywhere: A TED speaker's worst nightmare'}

According to 'incongruity' theories, humour is the "consequence of the discrepancy between two mental representations, one of which is an expectation and the other is some other idea or a percept" (Nerhardt 1977: 47). This discrepancy is context-bound: it is not related to the object of humour in itself, but rather to a situation that renders it unsuitable or contrastive to another object. In McGhee's (1979: 6-7) words:

the notions of congruity and incongruity refer to the relationship between components of an object, event, idea, social expectation, and so forth. When the arrangement of the constituent elements of 
an event is incompatible with the normal or expected pattern, the event is perceived as incongruous.

This is a fundamental element of TED talks, as humour is usually unexpected in science dissemination. In the sub-corpus of the 25 most viewed TED talks between 2006-2012 rated 'funny' by the TED community, there are 360 instances of laughter, and humour is generated from incongruity 105 times. In these cases, humour arises from the expectancy that science popularisation should be delivered in a 'serious' way, whereas in many occasions TED speakers surprise their audience with unexpected humorous situations.

Among the talks that were part of the sub-corpus, the most representative of this kind of humour is Eugene Cordero's 'Improv Everywhere: A TED speaker's worst nightmare'. The assumption that leads to humour and laughter in this talk is that presenting at TED is such a prestige that the talk must be absolutely flawless. Though the title gives the audience a hint on an unusual TED talk, the speaker introduces himself as 'Colin Robertson', starting a talk on discoveries in the solar technology industry. When the speaker introduces his first video, something unusual happens, the video cannot start:

Huh. Hang on a moment. It might take a moment to load.

At this point, though the inconvenience is unexpected for such an important context as TED, which is minutely organised in every single detail, the situation still seems normal, and so the speaker apologises and tries to continue his presentation. The audience are visibly uncomfortable as the technological problems started, and connect emotionally with the speaker who is apparently having a very negative experience, a 'nightmare' indeed. After about twenty seconds, the slides continue crashing one after the other and the Mac multicoloured 'error wheel' appears. Then an error message appears on the screen, followed by several others.

As the Mac 'error wheel' gets bigger, more of them appear on the screen. By this point, after a first incongruous moment, the audience understands that it is all part of the presentation and starts laughing:

We'll just - we can just skip - I'll just skip through the video

(Laughter)

instead...

(Laughter)

However, the situation gets even more humorous. Incongruity is in a crescendo, as suddenly ten people in the audience hold up some rainbow umbrellas and start spunning them. The audience still was not ready for the sprays of confetti, the people in rainbow clown hats who start dancing on stage, or the beach balls tossed among the orchestra, generating an unusual situation for the TED audience, full of humour and laughter.

The audience had not been told that Colin Robertson was actually a creation of Charlie Todd's Improv Everywhere, "a New York City-based prank collective that causes scenes of chaos and joy in public places". Robertson, played by Eugene Cordero, was part of their brilliant and energetic scene of the technical disaster gone flash mob staged at TED. Generating humour from incongruity, Colin Robertson challenged the stereotype of a flawless TED talk with an error-message-filled presentation until the audience realised that the entire presentation was all part of an Improv Everywhere stunt.

Therefore, starting from the incongruity of slides that did not work, increasing the eccentricity of the situation in a crescendo from turning umbrellas to a colourful dance with beach balls, Cordero breached the typical context of popularisation, connecting with his 
audience through an incongruous talk. The discrepancy generated by this talk is contextbound: what was happening contrasted with the social expectation of the context, it was incompatible with the normal pattern of TED talks, and, thus, the event was perceived as humorous because it was incongruous.

\subsection{Humour from derision: Sebastian Wernicke: 'Lies, damned lies and statistics (about TED talks)'}

Superiority theories of humour trace back to Aristotle and Thomas Hobbes. The general idea is that a person laughs about the misfortunes of others, because these misfortunes assert the person's superiority on the background of their shortcomings. According to this theory, whose main theorist is Thomas Hobbes (1999[1650]: 11.13):

the passion of laughter is nothing else but sudden glory arising from some sudden conception of some eminency in ourselves, by comparison with the infirmity of others, or with our own formerly.

Here, laughter is directed down at someone from a position of perceived superiority. In this kind of humour, laughter often arises from the act of making fun of someone. A particular form of application of this theory of humour is self-deprecation, which refers to the speakers deriding themselves and wanting their audience to laugh at their own expense. This technique can create a connection with the audience, breaching the barrier between the speaker and the public.

In the sub-corpus of the 25 most viewed TED talks rated 'funny' by the TED community, humour is generated from a sense of superiority 186 times out of 360 .

In the talk chosen as an example for this form of humour, the object of deprecation/derision is TED itself. Sebastian Wernicke, an engagement manager at Oliver Wyman and former bioinformatics researcher, explains the results deriving from his pseudoanalysis of TED talks. In this talk, Wernicke analyses the different factors that statistically characterise a successful or unsuccessful TED talk. Though the topic itself might not seem overly interesting, he livens up his performance by using humour and irony to slightly make fun of the entire TED system.

As Wernicke begins his talk, he shares some statistics about TED talks, such as how many days of content there are and how many ratings have been given on the site. He then uses these results to introduce the topic of his speech. The audience immediately understands that he is going to make fun of TED, exaggerating some features to create a humorous situation:

And it got me wondering: If you took all this data and put it through statistical analysis, could you reverse engineer a TED talk? Could you create the ultimate TED talk? (Laughter) (Applause) And also, could you create the worst possible TED talk that they would still let you get away with?

In this way, Wernicke immediately engages and entertains his audience. Then he uses statistics to deride the topics usually presented at TED. He shares the top ten most common words in the title of the most popular talks. The top five were "you", "happiness", "brain", "French", and "coffee". He then makes a joke, saying that if speakers really wanted to give a good talk, they should talk about how "French coffee spreads happiness to your brain". The audience laughs at this, as it is obviously not a very organised sounding topic. However, it was humorous, and it gave the audience energy, which made them more enthusiastic about what he was saying: 
Let's look at the list of top 10 words that statistically stick out in the most favourite TED talks and in the least favourite TED talks. So if you came here to talk about how French coffee will spread happiness in our brains, that's a go. (Laughter) (Applause) Whereas, if you wanted to talk about your project involving oxygen, girls, aircraft - actually, I would like to hear that talk, (Laughter) but statistics say it's not so good.

He also uses humour against the organisation, and its rigid schedule. In this case, laughter is also created by the incongruity of the imagining to be dragged off from the stage:

How should you deliver your talk? TED is famous for keeping a very sharp eye on the clock, so they're going to hate me for revealing this, because, actually, you should talk as long as they will let you. (Laughter) [...] talk until they drag you off the stage. (Laughter)

As he is sharing the four statistically best and worst phrases, he shares that "et cetera, et cetera" was good while "I do not know" was bad. He says that this shows that you do not need to know things; you just need to seem as if you do, because it makes you seem "smarter, intelligent, et cetera et cetera". Here he uses irony to prove his point. He also attacks the New York Times in a humours way:

Secondly, it's imperative that you do not cite The New Times. (Laughter) And finally, it's okay for the speaker - that's the good news - to fake intellectual capacity. If I don't understand something, I can just say, "etc., etc." You'll all stay with me. It's perfectly fine. (Applause)

Then, he derides one of the landmarks of TED talks: visuals. The speaker uses statistics to make fun of the colours used in power point presentations:

And now the most important thing, that is the mood onstage. Color plays a very important role. Color closely correlates with the ratings that talks get on the website. (Applause) For example, fascinating talks contain a statistically high amount of exactly this blue color, (Laughter) much more than the average TED talk. Ingenious TED talks, much more this green color, etc., etc. (Laughter) (Applause)

Finally, he teases the whole system by saying to use his "TEDPAD" to formulaically write a talk:

I learned from my analysis that I should actually give you something; I will not impose the ultimate or worst TED talk on you, but rather give you a tool to create your own. And I call this tool the TEDPad. (Laughter) And the TEDPad is a matrix of 100 specifically selected, highly curated sentences that you can easily piece together to get your own TED talk. You only have to make one decision, and that is: Are you going to use the white version for very good TED talks, about creativity, human genius? Or are you going to go with a black version, which will allow you to create really bad TED talks, mostly about blogs, politics and stuff? So, download it and have fun with it.

This shows the importance of humour used to deliver this speech. It intellectually deconstructs the whole system by using derision, in a light-hearted way.

\subsection{Humour from taboos: Julia Sweeney: 'It's time for 'The Talk'}

The third humour theory, the 'release' theory, is typically associated with Sigmund Freud and Herbert Spencer. These theorists posit that humour is used to release tensions or to make one feel liberated when talking about taboo topics, such as sex, politics, and religion.

Freud (1960[1905]) considers laughter to be "an outlet for psychic or nervous energy". In this perspective, humour may serve to express hostility, aggressiveness, or obscenity. Open access journal | EJHR: www.europeanjournalofhumour.org 
According to Freud, there is an underlying, unconscious thought which is responsible for the release of repressed feelings.

In the sub-corpus of the twenty five most viewed TED talks between 2006-2012 rated as 'funny' by the TED community, humour is generated from energy release 81 times.

In 'It's time for 'the talk', the Saturday Night Live comedian Julia Sweeney makes the audience part of the moment of her life when she had to explain sexuality to her then 8-yearold daughter. Unexpectedly, her daughter starts asking about the topic at a Thai restaurant, and so the speaker gives her hilarious version of what happened. In this case, humour is generated by the taboo topic of sexuality, which becomes even more humorous, being unexpected in the context of a public TED talk.

It must be said that the talk is actually retrieved from one of Sweeney's Saturday Night Live performances, 'Sex Ed.', which faced the topic even more overtly. ${ }^{6}$

The story begins with the child's innocent question about frog reproduction. In a crescendo, the child's questions get ever more inappropriate as the conversation goes on. As the text is a re-adapted excerpt from Saturday Night Live, it is an edulcorated and less vulgar version, more suitable to the context of TED talks:

\footnotetext{
"So, basically, frogs lay eggs and the eggs turn into tadpoles, and tadpoles turn into frogs."

And I said, "Yeah. You know, I'm not really up on my frog reproduction that much. It's the females, I think, that lay the eggs, and then the males fertilize them. [...]"

And she goes, "And what's this fertilizing?"

So I kind of said, "Oh, it's this extra ingredient, you know, that you need to create a new frog from the mom and dad frog." (Laughter)
}

The situation becomes more embarrassing when the child innocently asks about humans. Laughter is also produced here by ethos established with the audience, which empathises with the embarrassed woman, a parent who has to talk about sexuality with her daughter for the first time, and even worse, at a restaurant. The woman has to find a quick and a good answer to her daughter's question, trying to avoid triggering her curiosity:

And she said, "Oh, so is that true for humans too?"

I was trying to remember all the guidebooks, and all I could remember was, "Only answer the question they're asking. Don’t give any more information." (Laughter) So I said, "Yes.”

Humour is also given by the epigrammatic expression "don't give any more information", which then seems to be inapplicable to the curious child. The woman tries to be as technical and serious as possible, but then another question about human reproduction generates a burst of laughter:

Her jaw just drops, and she goes, "Mom! Like, where you go to the bathroom?"

And I said, "I know. I know." (Laughter) "That's how we evolved. It does seem odd. It is a little bit like having a waste treatment plant right next to an amusement park... Bad zoning, but..." (Laughter)

In a crescendo, the child then gives rise to one of the most famous punch lines of the talk, which is humorous not only for the erotic topic, but also as it derides men ridiculing them:

And then she said, "But how does it happen when a man and woman are together? Like, how do they know that's the time? Mom, does the man just say, 'Is now the time to take off my pants?'” (Laughter)

And I said, "Yes." (Laughter) "That is exactly right. That's exactly how it happens." 
The next section makes the audience empathise even more with the speaker and it reveals that the woman has adopted the child because she cannot have children. Though having experienced this sad condition, the speaker makes a laugh out of it, through her daughter's words:

And she said, "Mom, have you done this before?"

And I said, "Yes."

And she said, "But Mom, you can't have kids." Because she knows that I adopted her and that I can't have kids.

And I said, "Yes."

And she said, "Well, you don't have to do that again."

And I said, "..."

The talk continues when the family goes home. The child is not content with her mother's replies, so she questions further, until her mother decides to decline her responsibility by using the internet for some research:

And she goes, "But I just can't understand it."

So I go, "You know, why don’t we go on the Internet, and maybe we can see... like on Wikipedia."

(Laughter)

So we go online, and we put in "cats mating."

Her punch line is a climax of incongruity, deprecation, and relief, as the woman decides to solve the issue of human sexuality once and for all:

And then she goes, "Mom, do you think they would have, on the Internet, any humans mating?" (Laughter) And then I realized that I had taken my little eight year old's hand, and taken her right into Internet porn. (Laughter)

The Saturday Night Live version of this talk continues with the child enquiring upon homosexuality, but the speaker has chosen to leave this part out of the TED talk, perhaps either due to time limitations, or due to topic inappropriateness in the TED community context.

This last talk may be seen as a perfect blend of the three modalities of engaging with the audience through the use of humour, as its topic is quite unusual for the TED context (incongruity), it makes fun of a human condition, especially of men (derision/superiority), and it generates laughter by talking about the sex taboo (release).

\section{Conclusions}

The talks analysed as examples in this paper have shown how humour is used as an endemic feature of TED talks. In contrast with other forms of 'canonical' popularisation, these talks are not only delivered in a simple, clear, original, and relevant way, but also in a way that is enjoyable for the audience, which engages with the speaker through humour.

Humour is generated from incongruity when the arrangement of the elements of an event is incompatible with the normal or expected pattern, as seen in the case of Eugene Cordero's talk 'Improv Everywhere: A TED speaker's worst nightmare', in which the assumption that leads to humour and laughter is that presenting at TED is such a prestige that the talk must be absolutely perfect. Humour can also derive from laughter directed down at someone from a position of perceived superiority, in which the speaker makes fun of someone or of something looking at it from above, as in Sebastian Wernicke's 'Lies, damned lies and 
statistics (about TED talks)', which intellectually deconstructs the whole TED system by using humorous statistics against it, in a light-hearted way that does not offend anyone overtly. Finally, humour can also be used to release tensions or to make one feel liberated when talking about taboo topics, such as sex, politics, and religion, as in Julia Sweeney's 'It's time for "The Talk", in which laughter gives the permission to talk about a forbidden topic without offending the audience's positive face.

Naturally, this paper is limited to three individual case studies, but it does reveal some interesting issues about popularisation. An important feature related to the use of humour in online popularisation is certainly that the medium of communication has an important impact both on the use and reception of humour and on the overall content of TED talks. In other words, the potentially world-wide audience influences the choice of the humorous features that are part of these popularising speeches. In fact, TED talks prefer to include globally oriented humorous elements rather than locally oriented topics. Globally oriented humour (Shifman 2007) deals with features that are common to societies all over the world. Humorous texts about taboos, incongruities, and sense of superiority, such as those seen in the examples analysed above and used in TED talks in general, are based on shared universal categories. In contrast, TED talks avoid locally oriented humour related to culture-specific elements such as local politics, language, and ethnicity. This kind of humour would not help the purpose of knowledge dissemination because it would limit comprehension when the videos are viewed by the world-wide internet audience.

Furthermore, the internet medium facilitates the use of humour because it has the capacity to convey and combine all existing communication forms, such as the use of script and sound, pictures and videos, and it also allows storing and spreading digitised content at a world-wide level (Bolter \& Grusin 1999). The internet aids the overall purpose of popularisation because it contributes to McLuhan's ideal of a 'global village', as it has transformed passive TV viewers into active and global village citizens (Levinson 1999). The new medium and the use of humour form a perfect bond to achieve the purpose of knowledge dissemination through popularisation, because the audience contributes to the spread of these videos. In this way, TED talks have the advantage of reaching a far broader audience than offline popularised scientific communication.

However, the use of humour in popularisation in this 'globalised' context opens the opportunity for further studies to establish the possible downsides for the genre. In fact, there might be some limits to using humour in scientific popularisation, particularly in relation to online communication, as it can risk becoming a form of 'infotainment' rather than knowledge dissemination. According to Hartz \& Chappell (1997), already in the late 1990s, 75 per cent of scientists agreed that "the media, when covering science, are more interested in sensationalism than truth and that media coverage concentrates too much on trend discoveries rather than basic research and development". Future research could seek to discern more details about the delicate balance and challenge between online science popularisation and 'infotainment', for a more comprehensive interpretation of TED talks.

\section{Notes}

[1] TED website: www.ted.com (last accessed: July 2013).

[2] Ideas on Stage: http://www.ideasonstage.com/?lang=en (last accessed: August 2013).

[3] Source: http://philpresents.wordpress.com/tag/ted-com/ (last accessed: August 2013).

[4] For further information on pathos in speeches, see Aristotle, On Rhetoric; available at: http://classics.mit.edu/Aristotle/rhetoric.html

[5] For further information: http://improveverywhere.com/ (last accessed: August 2013). 
[6] Source: http://www.youtube.com/watch?v=Ry-LwxR746s (last accessed: August 2013).

\section{References}

Aristotle. (1968). Poetics. London: Oxford University Press.

Attardo, S. (1994). Linguistic Theories of Humor. Berlin \& New York: Mouton de Gruyter.

Bolter, J. D. \& Grusin, R. A. (1999). Remediation: Understanding New Media. Cambridge, Mass. \& London: MIT Press.

Calsamiglia, H. \& van Dijk, T. A. (2004). 'Popularization discourse and knowledge about the genome'. Discourse \& Society 15 (4), pp. 369-389.

Chovanec, J. \& Ermida, I. (eds.) (2012). Language and Humour in the Media. Newcastle upon Tyne: Cambridge Scholars Publishing.

Cordero E. (2012). 'Improv Everywhere: A TED speaker's worst nightmare'. http://www.ted.com/talks/a_ted_speaker_s_worst_nightmare.html

Demers, D. (2005). Dictionary of Mass Communication and Media Research: A Guide for Students, Scholars and Professionals. Spokane, WA: Marquette Books.

Donovan, J. (2012). How to Deliver a TED Talk: Secrets of the World's Most Inspiring Presentations. New York: McGraw-Hill.

Freud, S. (1960[1905]). Jokes and their Relation to the Unconscious. (Translated by Strachey, J.). New York: W. W. Norton.

Gumperz, J. J. (1982). Discourse Strategies. Cambridge: Cambridge University Press.

Hartz, J. \& Chappell, R. (1997). Worlds Apart: How the Distance between Science and Journalism Threatens America's Future. Nashville, TN: First Amendment Center.

Hazlitt, W. (1964[1891]). 'Lectures on the comic writers, etc. of Great Britain. Lecture 1 Introductory: On wit and humour', in Lauter, P. (ed.), Theories of Comedy, Garden City, New York: Anchor Books Doubleday \& Company Inc.

Hertzler, J. O. (1970). Laughter: A Socio-Scientific Analysis. New York: Exposition Press.

Hobbes, T. (1999[1650]). Human Nature and de Corpore Politico. New York: Oxford University Press.

Ideas on Stage. (n.d.). http://www.ideasonstage.com/?lang=en

Levinson, P. (1999). Digital McLuhan: A Guide to the Information Millennium. London: Routledge.

McGhee, P. (1979). Humor, its Origin and Development. San Francisco: W. H. Freeman and Company.

Nerhardt, G. (1977). Incongruity and Humour. Reports from the Department of Psychology, the University of Stockholm. Stockholm: Department of Psychology, University of Stockholm.

Oring, E. (2003). Engaging Humor. Urbana \& Chicago, IL: University of Illinois Press.

Raskin, V. (1985). Semantic Mechanisms of Humor. Dordrecht: Reidel.

Ross, A. (1998). The Language of Humour. London: Routledge.

Scott, A. N. (2012). Funnily Serious: Using Comedy to Communicate Science. Otago: University of Otago MA thesis (available at: http://hdl.handle.net/10523/2296).

Shifman, L. (2007). 'Humor in the age of digital reproduction: Continuity and change in Internet-based comic texts'. International Journal of Communication 1, pp. 187-209.

Sweeney, J. (2010). 'It's time for 'The Talk".

http://www.ted.com/talks/julia_sweeney_has_the_talk.html

Sweeney, J. (2010). 'Sex Ed'. http://www.youtube.com/watch?v=Ry-LwxR746s 
Waknell, P. (2012). 'How to make a great TED talk'. http://philpresents.wordpress.com/2012/03/12/how-to-make-a-great-ted-talk/ Wernicke, S. (2010). 'Lies, damned lies and statistics (about TED talks)'.

http://www.ted.com/talks/lies_damned_lies_and_statistics_about_tedtalks.html 